\title{
Probable E3 Ubiquitin-Protein Ligase DTX2
}

National Cancer Institute

\section{Source}

National Cancer Institute. Probable E3 Ubiquitin-Protein Ligase DTX2. NCI Thesaurus.

Code C106468.

Probable E3 ubiquitin-protein ligase DTX2 (622 aa, $\sim 67 \mathrm{kDa}$ ) is encoded by the human DTX2 gene. This protein plays a role in regulation of cell-cell communication during cell fate determination. 